Res., Soc. Dev. 2019; 8(3):e1583823

ISSN 2525-3409 | DOI: http://dx.doi.org/10.33448/rsd-v8i3.823

\title{
O Ensino de Física Moderna baseado no filme Interestelar: Abordagem didática para a aprendizagem significativa
}

The Modern Physics Teaching based on the Interstellar film: A didactic approach to meaningful learning

\section{La Enseñanza de Física Moderna basada en la película Interestelar: Enfoque didáctico para el aprendizaje significativo}

Fábio Andrade de Moura

ORCID: https://orcid.org/0000-0002-9778-5590

Instituto Federal de Educação, Ciência e Tecnologia do Pará, Brasil

E-mail: fabio.moura@ifpa.edu.br

Pedro Oliveira Vianna

ORCID: https://orcid.org/0000-0001-7360-185X

Instituto Federal de Educação, Ciência e Tecnologia do Pará, Brasil

E-mail: pedrooliveiraviana18@gmail.com

Recebido: 03/12/2018 | Revisado: 07/12/2018 | Aceito: 19/12/2018 | Publicado: 21/12/2018

\section{Resumo}

O ensino de Física vem ao longo dos anos passando por diversos desafios e dificuldades. Visando melhorar o ensino e aprendizagem dos alunos, tem-se buscado gerar novas abordagens que promovam a aprendizagem significativa. Devido incontáveis fatores, o ensino de Física Moderna nas escolas de Ensino médio tem sido deixado em segundo plano, fazendo com que os alunos não vivenciem esta área fundamental da Física. Este artigo tem como objetivo contribuir com o ensino de Física Moderna, em escolas estaduais da cidade de Bragança-PA, buscando mostrar aos alunos os conceitos fundamentais da Física Moderna de maneira simples e contextualizada com o apoio do filme Interestelar. O trabalho foi realizado nos períodos de abril a dezembro de 2017, na escola estadual Rio Caeté, sendo dividido em três etapas: Etapa I, constituída de uma avaliação diagnóstica e aulas de Física Moderna; Etapa II, Filme Interestelar e avaliação conceitual; Etapa III; aulas de física Moderna com um novo olhar, avaliação final e pesquisa de opinião. O projeto levanta discussões pertinentes a respeito do uso da avaliação diagnóstica, o uso de filmes no ensino da Física e mostra o sentimento dos alunos a respeito do ensino e aprendizagem de Física, mostrando em seus resultados uma amostragem considerável de aprendizagem significativa e evidenciando que é 
necessário criar novas formas de transmitir o conhecimento visando à aprendizagem significativa.

Palavras-chave: Ensino-aprendizagem; Avaliação diagnóstica; Conhecimento prévio.

\begin{abstract}
The teaching of Physics has over the years gone through various challenges and difficulties. In order to improve teaching and learning of students, we have tried to generate new approaches that promote meaningful learning. Due to countless factors, the teaching of Modern Physics in high schools has been left in the background, causing students not to experience this fundamental area of Physics. This article aims to contribute to the teaching of Modern Physics in state schools in the city of BragançaPA, seeking to show students the fundamental concepts of Modern Physics in a simple and contextualized way with the support of the Interstellar film. The work was carried out in the periods of April to December of 2017, in the Rio Caeté state school, being divided in three stages: Stage I, constituted of a diagnostic evaluation and classes of Modern Physics; Step II, Interstellar Film and Conceptual Evaluation; Step III; Modern physics classes with a new look, final assessment and opinion polls. The project raises pertinent discussions regarding the use of diagnostic evaluation, the use of films in Physics teaching and shows the students' feelings regarding teaching and learning of Physics, showing in their results a considerable sampling of meaningful learning and evidencing that it is necessary to create new ways of transmitting knowledge for meaningful learning
\end{abstract}

Keywords: Teaching-learning; Diagnostic evaluation; Previous knowledge

\title{
Resumen
}

La enseñanza de la física viene a lo largo de los años pasando por diversos desafíos y dificultades. Con el fin de mejorar la enseñanza y el aprendizaje de los alumnos, se ha buscado generar nuevos enfoques que promuevan el aprendizaje significativo. Debido a incontables factores, la enseñanza de Física Moderna en las escuelas de Enseñanza Media ha sido dejada en segundo plano, haciendo que los alumnos no vivan esta área fundamental de la Física. Este artículo tiene como objetivo contribuir con la enseñanza de Física Moderna, en escuelas estatales de la ciudad de Bragança-PA, buscando mostrar a los alumnos los conceptos fundamentales de la Física Moderna de manera simple y contextualizada con el apoyo de la película Interestelar. El trabajo fue realizado en los períodos de abril a diciembre de 2017, en la escuela estatal Rio Caeté, siendo dividido en tres etapas: Etapa I, constituida por una evaluación diagnóstica y clases de Física Moderna; Etapa II, Película Interestelar y evaluación conceptual; Etapa III; clases de física moderna con una nueva mirada, evaluación final y búsqueda de opinión. El proyecto levanta discusiones relevantes acerca del uso de la evaluación diagnóstica, el uso de películas en la enseñanza de la Física y muestra el sentimiento de los alumnos acerca de la enseñanza y el aprendizaje de Física, mostrando en sus resultados un muestreo considerable de 
aprendizaje significativo y evidenciando que es es necesario crear nuevas formas de transmitir el conocimiento para el aprendizaje significativo.

Palabras clave: Enseñanza-aprendizaje; Evaluación diagnóstica; Conocimiento previo.

\section{Introdução}

Ao estudar os conceitos sobre aprendizagem significativa, conseguimos observar que existem diversos estudos com o objetivo de entender como a aprendizagem funciona, e, ao procurar essas respostas, percebe-se que existem, dentro de uma mesma sala de aula, alunos que conseguem aprender com mais facilidade o conteúdo ministrado pelo professor que outros (ANTUNES, 2002, p.08).

Moreira (2006) considera que as metodologias de aprendizagem estão cada vez mais se distinguindo da estrutura cognitiva e realizando a reconciliação integradora de modo a identificar semelhanças e diferenças e reorganizar seu conhecimento, ou seja, o aprendiz constrói e produz seu conhecimento. No contexto desta pesquisa, se analisará a aprendizagem ao ministrar aulas de Física Moderna.

O Ensino de Física Moderna é componente curricular do terceiro ano do Ensino Médio. Segundo os Parâmetros Curriculares Nacionais - PCN (BRASIL, 2002), ele é fundamental para o processo de formação do cidadão e sempre vem proposto nos últimos capítulos dos livros do $3 .^{\circ}$ ano do Ensino Médio. Somado ao fato das escolas públicas terem uma reduzida carga horária para a Física, os conteúdos programáticos de Física Moderna, Quântica e Nuclear geralmente não são ensinados de forma satisfatória e, em alguns casos, esses conteúdos nem sequer são ministrados pelos professores.

A deficiência no Ensino de Física Moderna causa prejuízos na formação dos estudantes, pois dificulta a compreensão de muitos dos aspectos tecnológicos do mundo contemporâneo, como as telecomunicações com e sem fio, a aplicação Física na área da medicina, engenharias, funcionamento de aparatos tecnológicos de uso diário como smartfones, computadores, CD's, DVD's, internet, etc.

Para contribuir com o ensino de Física Moderna em escolas estaduais da cidade de Bragança-PA, realizou-se esta pesquisa durante o ano de 2017, através de um projeto de extensão denominado Física Moderna com uma abordagem didática para a Aprendizagem Significativa. O projeto teve como objetivo levar aos alunos os conceitos fundamentais da Física Moderna de maneira simples e contextualizada, com o apoio do filme Interestelar.

O objetivo deste artigo é apresentar os resultados do projeto de extensão Física 
Moderna com uma abordagem didática para a Aprendizagem Significativa, além de demonstrar as dificuldades dos alunos participantes da pesquisa e expor os resultados das avaliações realizadas durante o projeto.

\section{Fundamentação Teórica}

O processo de ensino-aprendizagem precisa superar os desafios que aparecem nas escolas e um desses desafios é fornecer ao aluno uma explicação aos fenômenos da natureza de forma simples com abordagens que conduzem a aprendizagem significativa sobre os fenômenos da Física. Para Moreira e Masini (2006), o processo de ensino-aprendizagem está progressivamente diferenciando sua estrutura cognitiva e fazendo a reconciliação integradora de modo a identificar semelhanças e diferenças e reorganizar seu conhecimento, ou seja, o aprendiz constrói seu conhecimento e, também, produz seu conhecimento.

Moura (2018) destaca a importância dos papéis do professor e do aluno no processo de ensino-aprendizagem. O autor considera "como pontos primordiais o papel do professor, que precisa planejar nos mínimos detalhes essa metodologia de ensino, e ao aluno, como ser pensante e ativo durante todo o processo no ensino" (MOURA, 2018, p.67). Concordando com autor, Moura e Mandarino (2017, p.3) afirmam que as atividades de ensino que requerem pesquisa e investigação dos alunos "é um meio útil e viável para melhorar o processo de ensino-aprendizagem e quando associados à aula bem planejada, torna o ensino de Física agradável, estimulante ao aluno e satisfatório nas avaliações de aprendizagem”.

O desafio apresentado nesta pesquisa é ensinar os conceitos de Física Moderna para alunos da rede estadual de ensino com o aporte do filme Interestelar. O filme, que foi lançado em 2014, apresenta vários conceitos sobre Física Moderna e Quântica, além de trazer conceitos importantes da Astronomia. Sobre a utilização de filmes em sala de aula, Morán (1995, p.27) afirma que os filmes "aproximam a sala de aula do cotidiano, das linguagens de aprendizagem e comunicação da sociedade urbana, e introduz novas questões no processo educacional".

Para o autor, o uso de filmes no ensino se torna importante por ter como características os aspectos sensoriais, visuais, linguagem falada, musical e escrita. Linguagens que interagem superpostas, interligadas, somadas, não separadas. Resumindo, os alunos são contemplados por todos os sentidos e de todas as maneiras.

O filme, como recurso didático, funciona como uma fonte de inspiração e possibilita trazer aos alunos uma realidade diferente do habitual, promovendo diversas aplicações científicas sobre vários fenômenos físicos (BRITO; NOLASCO, 2011, p.1). A ficção 
científica tem sua própria maneira de falar sobre a ciência, pois é didática, porque se propõe a veicular ideias, mas não no sentido de explicar o que é a ciência ou ensinar conceitos científicos, embora isso possa ocorrer ocasionalmente (PIASSI, 2013, p.12). Novamente se enfatiza que a escolha do filme ocorreu devido a sua fidelidade aos conceitos físicos que permitem elaborar roteiros de aulas para que os alunos aprendam os significados dos conceitos abordados.

Moreira e Masini (2006) apontam que os significados são pontos de partida para a atribuição de outros significados, constituindo-se em pontos básicos de ancoragem, dos quais se origina a estrutura cognitiva. Ressalta-se que a estrutura cognitiva aporta e organiza as informações de qualquer modalidade do conhecimento, armazenadas pelo estudante, conduzindo-o à aprendizagem cognitiva. Concordando com os autores, Mandarino; Silva; Moura e Vianna (2017) afirmam que os projetos de ensino, pesquisa e extensão desenvolvidos em escolas "unem as teorias da aprendizagem significativa, os Parâmetros Curriculares Nacionais e o Ensino de Física para melhorar o processo de ensino-aprendizagem” permitindo construir uma aprendizagem significativa prevista pelos PCNs.

Analisando os PCNs, percebe-se que a Física apresenta um conjunto de competências que permitem aos alunos perceber e lidar com os fenômenos naturais e tecnológicos contidos no dia-a-dia. Desta forma, é possível elaborar metodologias que possam transpor o conhecimento de uma física teórica para usos mais práticos, e para isso, é feita a contextualização destes temas para que seja possível trazer para a realidade prática e tangível do aluno.

A contextualização tem muito a ver com a motivação do aluno, por dar sentido àquilo que ele aprende, fazendo com que relacione o que está sendo ensinado com sua experiência cotidiana. Através da contextualização, o aluno faz uma ponte entre teoria e a prática, o que é previsto na $L D B$ e nos Parâmetros Curriculares Nacionais (Brasil, 1998).

Ao analisar o ensino de Física Moderna, onde os fenômenos ocorrem em escala quântica, planetárias ou com velocidade comparável à velocidade da luz, essa contextualização com o dia a dia do aluno se torna quase inviável. Analisando esse contexto, os PCNs consideram importante ressaltar que a aquisição do conhecimento vai além de conhecer fórmulas e saber como aplicá-las, o conhecimento envolve a aprendizagem do conceito por trás desta equação. 
Res., Soc. Dev. 2019; 8(3):e1583823

ISSN 2525-3409 | DOI: http://dx.doi.org/10.33448/rsd-v8i3.823

A aquisição do conhecimento, mais do que a simples memorização, pressupõe habilidades cognitivas lógico-empíricas e lógico-formais. Alunos com diferentes histórias de vida podem desenvolver e apresentar diferentes leituras ou perfis conceituais sobre fatos físicos, que poderão interferir nas habilidades cognitivas. $O$ aprendizado deve ser conduzido levando-se em conta essas diferenças (BRASIL, 2002).

Para trazer esse conhecimento teórico para mais próximos do aluno de forma que ele possa compreender os fenômenos da Física, buscou-se o auxílio de filmes como forma de trazer esse conhecimento para o aluno de forma simples. Segundo Oliveira (2006), é importante apontar o cinema como veículo de formação do imaginário social concernente à Ciência. A ausência de exploração desse potencial e do recurso cinematográfico, com esse intuito pode ser considerada uma perda, visto que o cinema atinge o sujeito de maneira particular através da identificação e da sensibilização.

Dessa forma, procurou-se ligar o conhecimento de física moderna com o uso do filme interestelar para servir como suporte para a transição do conhecimento, criando uma ponte entre o conhecimento teórico que seria apresentado em sala e a apresentação cinematográfica destes fenômenos, de modo que o aluno possa compreender o conceito e não só usá-lo para realizar cálculos matemáticos.

Observando a aprendizagem significativa (MOREIRA; MASINI, 2006), os Parâmetros Curriculares Nacionais (BRASIL, 2002), o fato de o conteúdo programático de Física Moderna sempre vir proposto nos últimos capítulos dos livros do $3^{\circ}$ ano do Ensino Médio e somado ao fato de as escolas públicas terem reduzida carga horária, propôs-se através desta pesquisa, articular um trabalho dentro da sala de aula para ministrar os conteúdos de Física Moderna, Quântica e Astrofísica de forma interativa, tendo como aporte principal o Filme Interestelar. Através dessas aulas serão produzidos materiais e meios de identificar o quanto os alunos realmente aprenderam o conhecimento ministrado.

\section{Metodologia}

A partir da fundamentação teórica, partimos para a metodologia aplicada nesta pesquisa e concordamos com Godoy (1995) ao analisar que a pesquisa qualitativa permite analisar os dados e conduzir as discussões para dialogar com os resultados. Apesar de basearmos nos trabalhos de Godoy, consideramos que este artigo possui características de uma pesquisa qualiquantitativa, pois os dados qualitativos se sobressaem aos dados 
quantitativos.

Para alcançar os objetivos, dividimos a pesquisa em 03 etapas que foi executada em duas turmas de primeiro e terceiro ano do Ensino Médio da Escola de Ensino Fundamental e Médio Rio Caeté em Bragança, no estado do Pará. Cada etapa foi ministrada no período de abril a dezembro de 2017, na escola selecionada. As etapas do projeto obedecem a seguinte ordem: ETAPA I - Avaliação diagnóstica, que será utilizada para observar os conhecimentos prévios e/ou subsunçores dos alunos em relação aos assuntos que serão abordados neste projeto; Aula sobre Física Moderna, Quântica. ETAPA II - exposição do filme Interestelar; avaliação conceitual, que acontecerá em forma de debate formulado com base em um cronograma de questões sobre os conceitos Físicos apresentados no filme. ETAPA III - Aula sobre Física Moderna, Quântica e Astrofísica com um novo olhar; Avaliação final que será realizada um mês após as últimas aulas e sem avisar aos discentes, com uma avaliação que é uma mais elaborada, onde será exigida uma melhor formulação de respostas e assim, gerar uma base da aprendizagem significativa dos alunos. Junto com essa avaliação, foi feita uma pesquisa de opinião com os alunos, onde os mesmos responderiam questões acerca de suas visões do projeto.

\subsection{Etapa I}

Nas aulas de Gravitação Universal abordou-se o contexto histórico da Astronomia, iniciando a partir do modelo planetário geocêntrico defendido por Ptolomeu e a participação da Igreja Católica na propagação dessa ideologia, chegando até Nicolau Copérnico, que expôs os primórdios do modelo heliocêntrico e as consequências da criação desse novo modelo, evidenciando o grande impacto que essa teoria gerou no mundo cientifico, culminando em Galileu Galilei, que comprovou o modelo heliocêntrico através da observação do sistema solar, passando de Tycho Brahe e Johannes Kepler explicando as Leis de Kepler e suas aplicações no sistema solar, culminando em Isaac Newton, falando sobre a Gravitação Universal. Assim, usando essa base histórica e conceitual foi realizada a explanação a respeito de Campo Gravitacional, Aceleração da Gravidade, velocidade de escape e corpos em órbitas.

$\mathrm{Na}$ aula seguinte, trabalhou-se com o tema da teoria da relatividade para introduzir o tema, ocasião em que se explicou o conceito de espaço, falando sobre referencial, movimento e repouso e direções espaciais. Junto a isso, foi explicada a natureza do tempo e o conceito de simultaneidade para que com essa introdução, se conceituasse o espaço-tempo, a fim de que fosse possível explicar o conceito de transformações invariantes, fazendo ponte com a 
explicação do éter e as naturezas da ondulatória e corpuscular da luz, de modo a desmitificar a natureza da luz mostrada com experimentos lógicos de que a mesma não se propaga de forma instantânea e sim, através do vácuo com velocidade constante.

Em continuidade às abordagens teóricas, mostrou-se o experimento Michelson e Morley que comprova a inexistência do éter e explicou-se a forma como a luz viaja e, para finalizar, criou-se uma ilustração teórica para demonstrar todos esses conceitos. Com isso, foi introduzido o conceito da teoria da relatividade especial, mostrando os dois postulados desta teoria, trazendo, portanto, os conceitos de dilatação do tempo e contração do espaço, massa relativista e energia relativa, utilizando apenas conceitos e problemas teóricos para enfatizar os princípios e a utilização destes em contextos apontados pelos próprios alunos, como filmes e séries. Logo após, foram abordados os conceitos da relatividade geral fazendo ligação com o tema da aula passada, no que diz respeito à gravitação e concluiu-se com a relação entre elas, explicando o campo gravitacional e suas funções.

Nas últimas aulas os temas abordados foram os princípios da Física Quântica, fez-se, também, uma pequena introdução a respeito do que é a física quântica, com o intuito de estabelecer a relação entre termodinâmica e eletrodinâmica que gera física quântica tratando a forma como esse ramo da física estuda os fenômenos das partículas atômicas e subatômicas. Os modelos atômicos de Rutherford e Bohr foram explorados para introduzir os alunos no contexto histórico das partículas atômicas e explicou-se a composição do átomo, descrevendo o movimento dos eletros e seus níveis de energia e a liberação de energia dos elétrons, mostrando a partículas subatômicas (Neutrino, Elétron, Quarks, Glúon, Bósons, Fóton e Gráviton), passando para o conceito de corpo negro para apresentar as leis de Planck, de Stefan-Boltzmann e de Wien, explicando o efeito fotoelétrico e suas aplicações para o cotidiano. Em seguida, passou-se a falar sobre princípios da incerteza, fazendo experimentos lógicos como o gato de Schrödinger, para demonstrar logicamente o princípio da incerteza, embasamentos usados para explicar o conceito de universos múltiplos e múltiplas probabilidades de eventos, finalizando com as teorias das cordas de Stephen Hawking.

Após as aplicações de cada aula foram realizados momentos para esclarecer dúvidas e socializar os conhecimentos adquiridos com as aulas e, assim, observou-se que os temas despertaram dúvidas e interesse nos alunos.

\subsection{Etapa II}

A segunda etapa do projeto foi realizada com os alunos de cada turma onde foi 
apresentado o filme Interestelar e, após a aplicação do filme, foi realizada uma roda de discussão, momento em que os alunos puderam fazer suas considerações sobre o filme e com o auxílio do professor foi realizado um debate sobre os temas que possuíam ligação com as aulas que foram aplicadas na etapa anterior. O filme serviu para despertar o interesse dos alunos, além de propiciar assimilações entre os assuntos que foram ministrados na etapa anterior e o que foi visto na produção cinematográfica, bem como do que fora falado através dos debates, transformando essas informações em aprendizagem ou conhecimento significativo.

Após a apresentação do filme e os debates realizados foi possível analisar o entendimento dos alunos sobre o assunto através das dúvidas que surgiram, revelando uma quebra de apatia dos alunos em relação ao tema, pois agora já tinham visto nos filmes, a prática do que tinham ouvido em sala.

\subsection{Etapa III}

A terceira etapa consistiu em realizar aulas sobre os mesmos temas da primeira etapa (gravitação universal, teoria da relatividade e mecânica quântica), entretanto, estas aulas foram realizadas utilizando um novo olhar dos temas a partir dos conhecimentos que já foram adquiridos através do filme. Foram ministradas aulas de gravitação universal, focando na relação da gravidade com os corpos e sua reação com a massa dos objetos, formas que a gravidade interfere no cotidiano, mostrando a interação gravitacional sobre os planetas e outros corpos celestes.

Após isso, foram ministradas aulas de relatividade para mostrar a ação de ondas gravitacionais, a demonstração de experimentos práticos de dilatação do tempo e exercícios teóricos para o entendimento de dilatação do tempo, de como este se contrai quando se aproxima da velocidade da luz, destacando de que formas a relatividade se apresenta no dia a dia e das descobertas científicas e avanços tecnológicos que foram conquistados a partir dessa nova área da física.

Foram ministradas aulas de introdução a Quântica para que os alunos percebessem a importância do estudo das subpartículas, suas aplicações práticas na formação de energia e matéria, relacionando-as a objetos conhecidos pelos alunos como micro-ondas, leitores de proximidade e placas de energia solar. Esta etapa foi realizada em três encontros com aulas de forma participativa e comparativa, onde foram utilizadas algumas cenas do filme Interestelar para gerar discussões e comparações com o filme, associando ao que era apresentado e o 
conhecimento que era reapresentado.

Ainda nesta etapa foi realizada uma prova após dois meses das aulas anteriores, com o intuito de analisar quais foram as informações que os alunos teriam sido capazes de torná-las significativas, tornando quantificativo o que até então era apenas qualitativo, e para isso foi ministrada uma prova conceitual, onde os alunos descreveriam com suas palavras os conceitos que foram apresentados. Junto com esta prova foi entregue uma pesquisa de opinião, onde os alunos avaliavam o projeto e seus próprios conhecimentos, quantos aos temas que foram apresentados.

\section{Resultados e Discussões}

\subsection{Etapa I}

Os resultados do projeto serviram para evidenciar a problemática proposta, quantificando as dificuldades dos alunos nas disciplinas de Português, Matemática e Física através da avaliação diagnóstica, conforme demonstrado na Figura 01, mostraram ainda, que apenas $44,5 \%$ dos alunos seriam capazes de retirar de um texto informações, tornando possível a sua interpretação, que apenas $21 \%$ destes alunos seriam capazes de decodificar os símbolos matemáticos, a fim de responderem os problemas propostos e apenas $16 \%$ dos alunos seriam capazes de interpretar problemas físicos, mostrando o quanto se torna difícil para que o professor possa observar estes fatores sem uma avaliação diagnóstica e que possa trabalhar com os alunos em suas dificuldades, a fim de melhorar a aprendizagem.

Figura 01: Resultado da avaliação diagnóstica

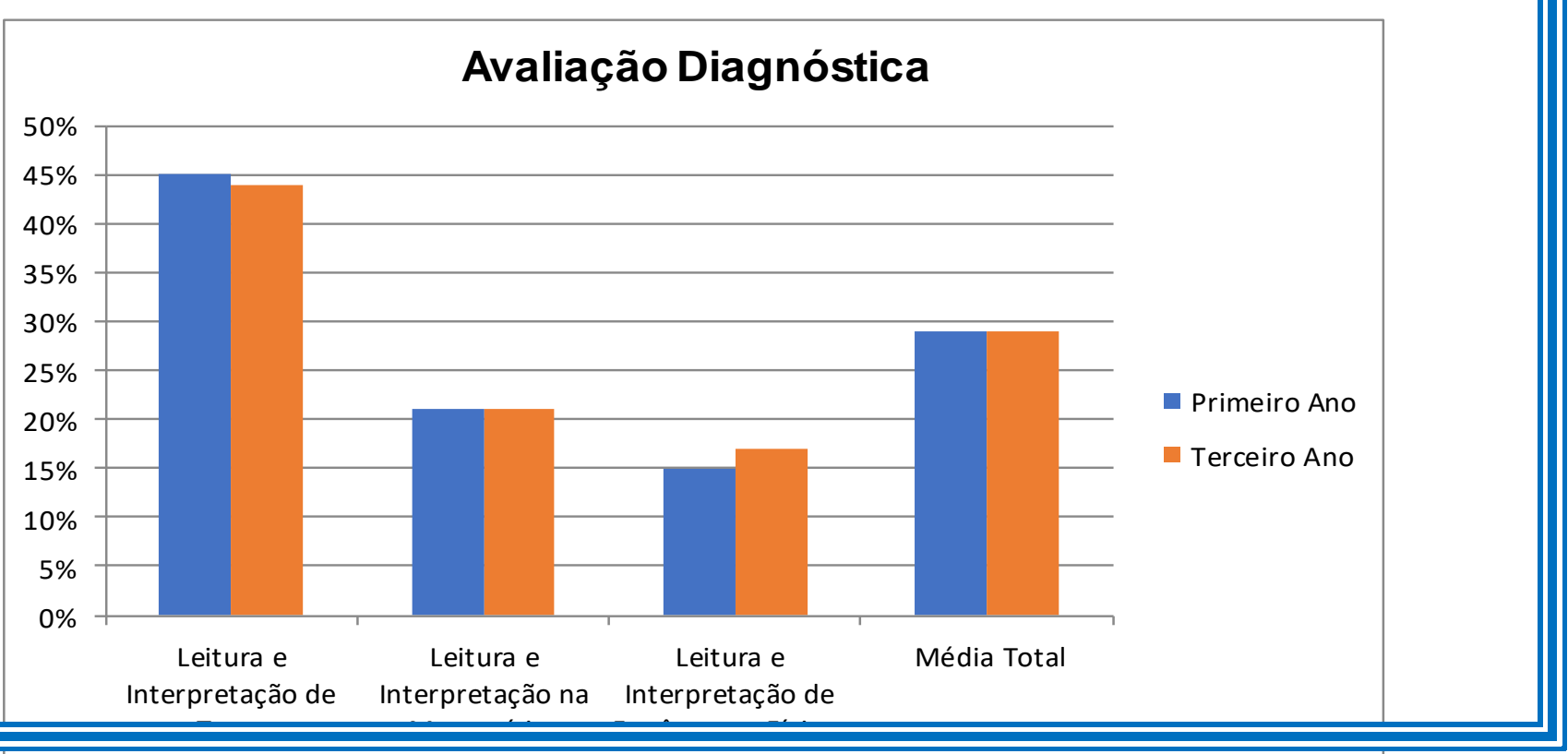


A partir do resultado da avaliação diagnóstica, observou-se que os alunos teriam dificuldades para trabalhar os temas abordados caso fosse utilizada uma linguagem matemática complexa. Mediante essa análise, todas as aulas que foram ministradas neste trabalho, foram focadas apenas nos conceitos e contextos dos fenômenos Físicos ao invés de trabalhá-los com operações puramente matemáticas, com a exceção de alguns exemplos de relatividade que foram explicados com o auxílio de problemas lógicos e cálculos simplificados.

Constatou-se que os alunos se sentiram mais confortáveis com o método de aula de Física voltado para o entendimento e explicação dos fenômenos, fugindo do modus operandi de aulas direcionadas para fórmulas e cálculos matemáticos, entretanto, muitos alunos sentiram dificuldade de interpretar o que estava sendo explicado, por serem incapazes de construir um método de conciliar as explicações com suas experiências cotidianas, esse fato ficou cada vez mais evidente a partir do momento em que a Física ganhava mais complexidade, aproximando-se da Física relativística e Quântica.

\subsection{Etapa II}

Nesta etapa foi realizada a seção do filme e a avaliação conceitual pós-filme. Essa avaliação foi feita na forma de discussões criadas pelos próprios alunos, logo a partir dos temas trabalhados no filme. Nesta avaliação, foram observadas as diferentes interpretações que os alunos tiveram quanto aos fenômenos apresentados. Devido ao tempo de duração do filme, não foi possível criar discussões mais longas a respeito do mesmo nessa etapa, mas foi evidente o interesse dos alunos pelos temas abordados durante o filme, criando também momentos pós-aula, onde foram tiradas dúvidas dos alunos, ajudando-os a produzir métodos próprios de raciocínio e comparação que ficou evidente mediante os resultados da próxima etapa, mostrando que os alunos conseguiram conciliar o que foi ministrado nas aulas e o que havia sido transmitido no filme, de forma que os próprios alunos criavam o seu modo de interpretar a física baseados em sua visão dos fenômenos.

\subsection{Etapa III}

Após a realização das avaliações diagnósticas, da sessão do filme e das discussões pós-filme, realizou-se a pesquisa de opinião, conforme Figura 02, onde os alunos tiveram a oportunidade de avaliar o projeto. 


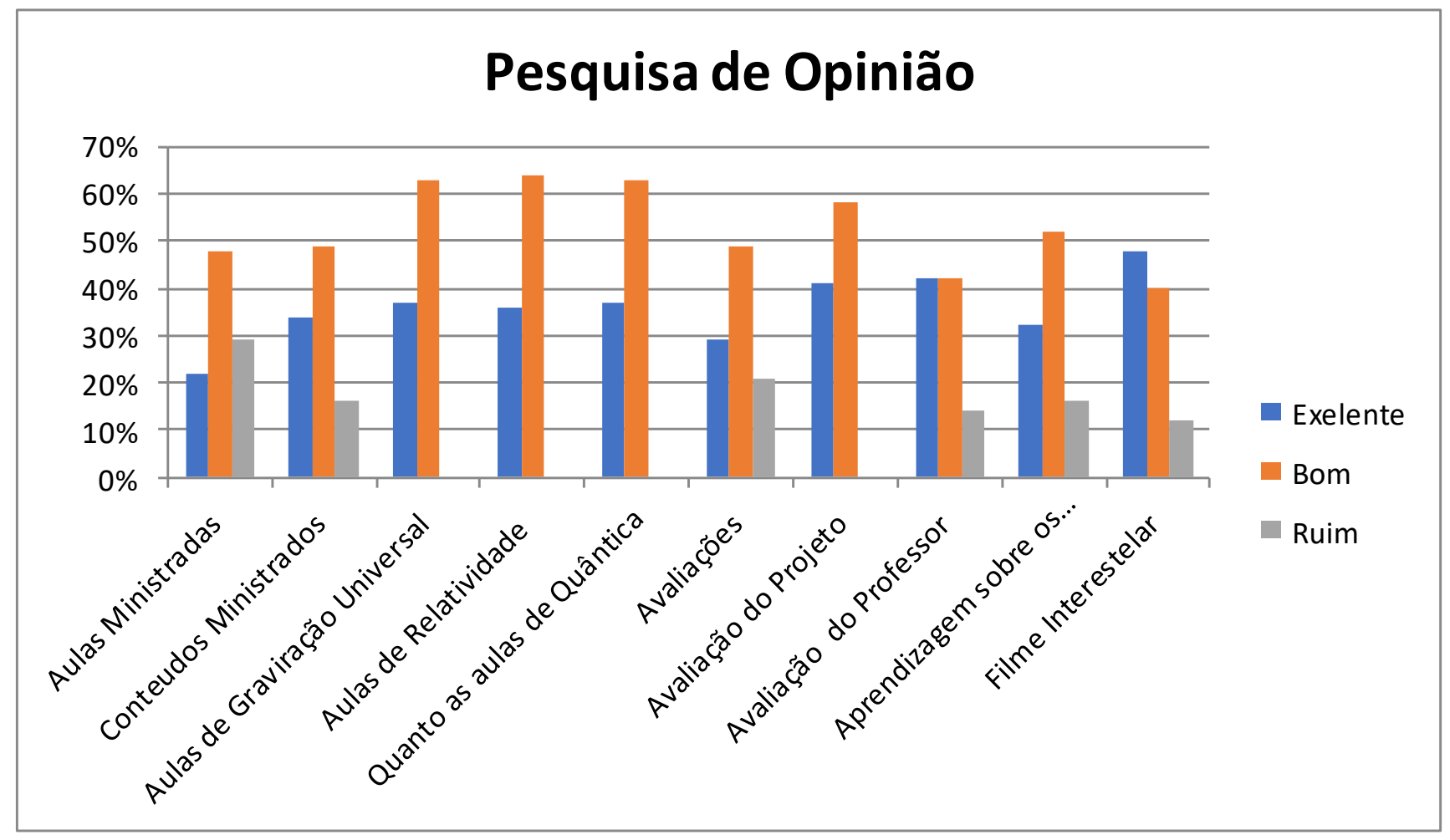

Fonte: Autor, 2018

A Figura 02 representa o resultado da pesquisa de opinião dos alunos e destacamos que em todos os pontos analisados a maioria dos alunos consideraram excelente ou bom cada tópico da pesquisa de opinião. No entanto destacamos o resultado ruim para o tópico de Aulas Ministradas onde quase $28 \%$ dos discentes afirmaram não terem gostado das aulas referente a esta etapa do projeto. Julgamos que esses valores foram devidos ao novo contexto em que as aulas foram ministradas, pois conforme avaliação diagnóstica não foi possível realizar aulas da maneira tradicional que os alunos estavam acostumados.

Aproveitando os tópicos de aula que foram ministrados durante esta pesquisa, solicitamos aos estudantes que realizassem uma autoanálise sobre o que eles compreenderam durante as atividades realizadas até este momento da pesquisa. Os resultados estão evidentes na Figura 03. 
Figura 03: Resultado da Autoanálise

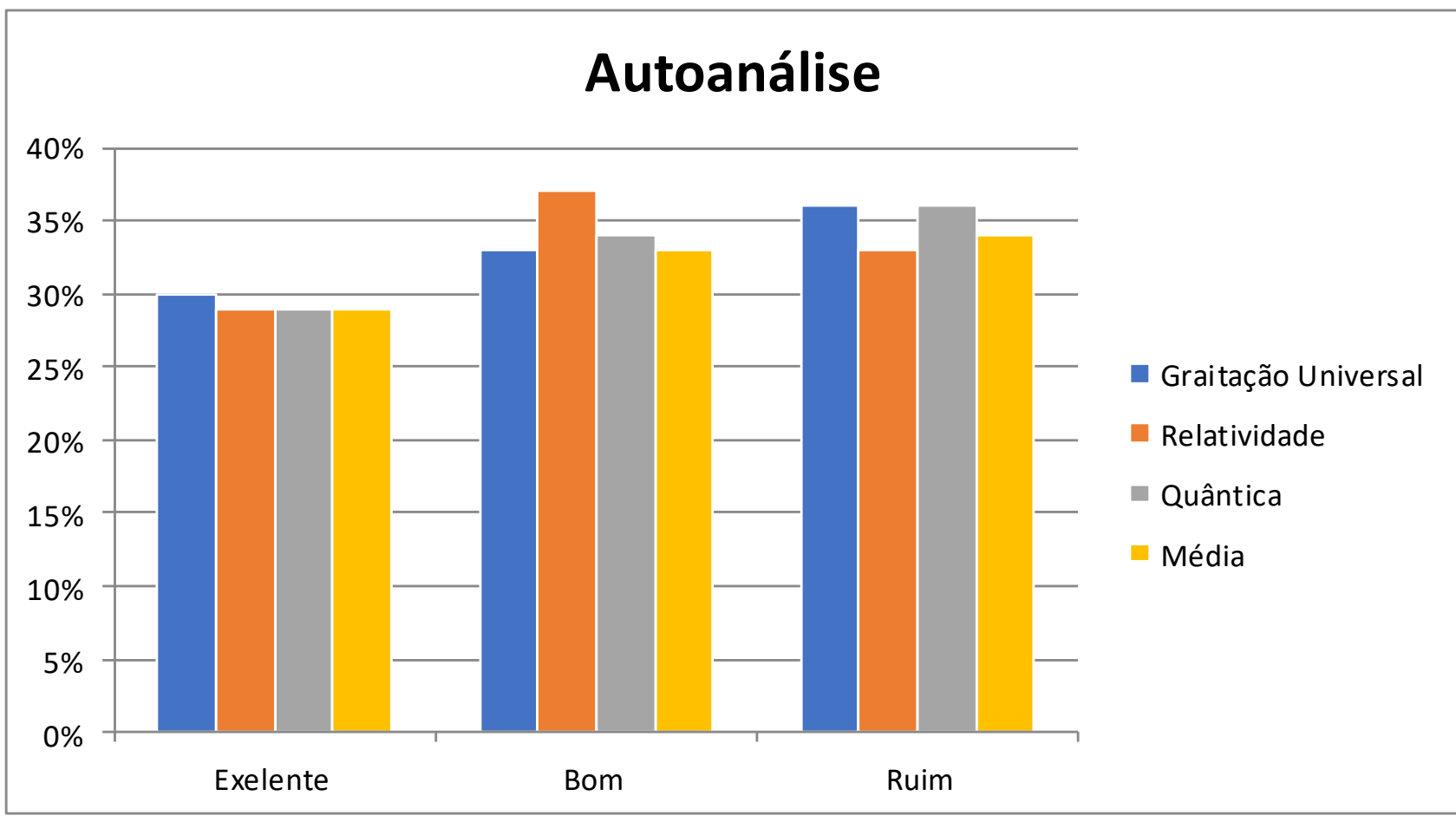

Fonte: Autor, 2018

A partir dos resultados, ficou perceptível como os alunos se sentiam a respeito dos temas abordados, como se vê na Figura 03, onde apenas 29\% dos alunos consideravam seu conhecimento excelente, $33 \%$ consideravam seu conhecimento bom e $34 \%$ consideravam seus conhecimentos ruins. Analisando os resultados, verificou-se que os discentes evidenciaram um sentimento de incapacidade para com seus próprios conhecimentos referentes aos temas que foram abordados no projeto.

Ao responderem a avaliação final, que era constituída de questões voltadas para a explicação dos conceitos que foram apresentados e tomando como base o resultado da autoanálise, seria esperada uma baixa aprendizagem devido ao fato dos alunos afirmarem sua incapacidade, fato que não ficou provado nos resultados da avaliação, conforme a Figura 4.

Figura 04: resultado a avaliação Final 


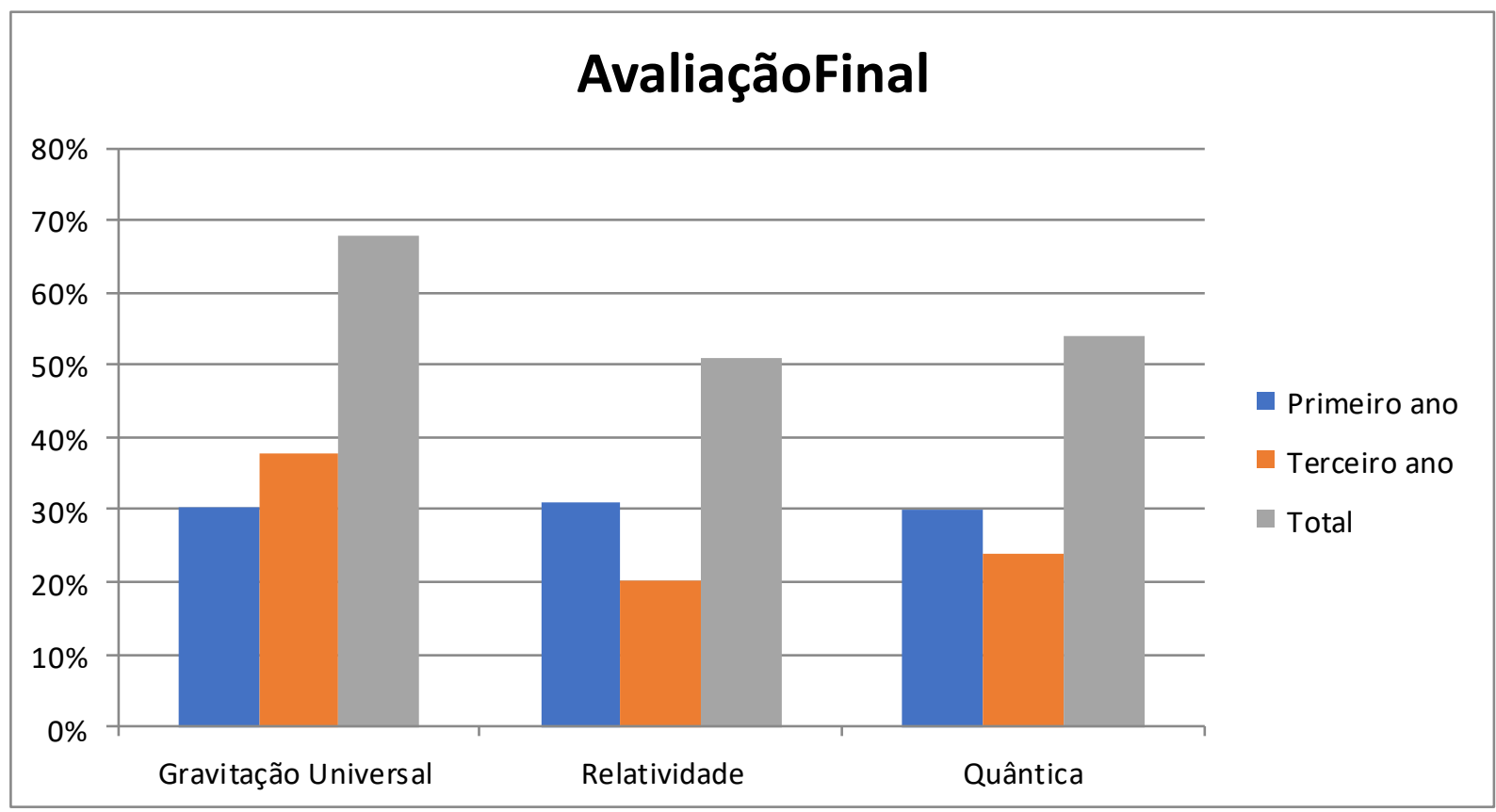

Fonte: Autor, 2018

Por meio da Figura 04, observamos que, os alunos conquistaram resultados positivos, conseguindo explicar o conceito de forma adequada, sendo que $68 \%$ dos alunos tiveram resultados positivos para o tema de Gravitação Universal, 51\% para tema de Teoria Relatividade e 54\% para o tema de Teoria da Física Quântica, ou seja, todos esses alunos conseguiram alcançar as expectativas de explicar o conceito que lhes foi apresentado, portanto, pode-se analisar que os alunos têm um sentimento negativo quanto a seus próprios conhecimentos, se sentindo incapazes de aprender determinados assuntos mesmo que saibam o conceito.

Analisando o contexto escolar e a metodologia do projeto, é possível compreender que a abordagem de uma metodologia de ensino incentive os alunos a criarem pontos de ancoragem para compreenderem os conhecimentos teóricos abstratos dos assuntos mais complexos da Física, fazendo com que sejam criados métodos de conciliar o que foi apresentado em sala com seu próprio conhecimento adquirido no cotidiano. Sendo esta abordagem indispensável para conseguir facilitar a construção de um conhecimento significativo, é necessário identificar as particularidades dos alunos através de uma avaliação diagnóstica e trabalhar sobre estas para incentivá-los a construírem novos conceitos sobre a física efetivando assim, a aprendizagem significativa.

\section{Considerações Finais}

O Trabalho buscou criar discussões e sugerir novos métodos para despertar o interesse 
e a aprendizagem dos alunos pela disciplina de Física, a partir das aulas de Física Moderna, com o envolvimento dos tópicos de Astrofísica, Relatividade e Quântica, com o auxílio do filme Interestelar, gerou discussões sobre temas abordados na disciplina a partir do filme, mostrou a importância da avaliação diagnóstica e da sensibilidade no momento de elaborar as aulas, sempre visando formas de trazer o conhecimento para o aluno de maneira que ele possa assimilar e juntar esses novos métodos com as aulas ministradas criando os subsunçores para ancorar esse novo conhecimento que será apresentado.

Embasado pela pesquisa de Moreira e Masini (2016), juntamente com os resultados obtidos nas avaliações diagnósticas realizadas no trabalho, ficou em evidência a dificuldade que alunos no Ensino Médio da escola Rio Caeté têm em relação às disciplinas de Física e Matemática, contribuindo, assim, para que aulas de Física sejam voltadas exclusivamente para cálculos e resolução de problemas difíceis de serem assimiladas. Para suprir essa necessidade, Brito e Nolasco (2011) afirmam a importância de filmes como fonte de inspiração capaz de trazer o aluno para uma nova realidade, aplicando o que é pedido nos PCN, sem relação com a contextualização de conteúdo.

Os resultados do trabalho de pesquisa mostram também um sentimento de incapacidade dos alunos quanto as suas habilidades de compreenderem os temas abordados, mostrando que, mesmo que tenha ficado evidente através dos resultados que os conceitos que lhes foram apresentados foram compreendidos, os mesmos não se julgam aptos a conceituarem os temas, pois se trata de conceitos que, para eles, estão muito além de suas capacidades.

Portanto, é possível concluir que, baseado nos dados e nos trabalhos apresentados, é necessário criar novas formas de se transmitir o conhecimento, visando sempre à compressão do aluno e acima de tudo, a sua aprendizagem Significativa.

Para finalizar, compreendemos que o ensino de Física com o aporte do filme Interestelar possibilita novas pesquisas na área de ensino, pois poderão ajudar a compreender as diferentes maneiras de como uma aula diferenciada pode contribuir para melhorar a aprendizagem dos alunos com o auxílio de alguma metodologia de ensino.

\section{Referências}

BRASIL. Ministério da Educação. Secretaria da Educação Média e Tecnológica. PCN: Parâmetros Curriculares Nacionais - ensino médio: ciências da natureza, matemática e suas tecnologias. Brasília: MEC. 1999. 
BRASIL. Ministério da Educação, Secretaria de Educação Média e Tecnológica. Linguagens, códigos e suas tecnologias: orientações educacionais complementares aos parâmetros curriculares nacionais - PCNS+. Brasília, 2002.

BRITO, Carlos Eduardo Costa de; NOLASCO, Diego. O. A Física dos filmes de Hollywood: Seria essa uma fonte segura de conhecimento?.2011. 20 f. TCC (Graduação) Curso de Física, Universidade Católica de Brasília, Brasília, 2011.

GODOY, A. S. Pesquisa Qualitativa: tipos fundamentais. Revista de Administração de Empresas, São Paulo, 35(3), 20-29, 1995.

MANDARINO, Pedro Henrique Pastana; SILVA, Sheila Cristina Porfírio da; MOURA, Fábio Andrade de; VIANNA, Pedro Oliveira. Projeto de Ensino e Extensão: Física Moderna com uma abordagem didática para a Aprendizagem Significativa. In: Congresso Nacional de Pesquisa e Ensino de Ciências, 2., 2017, Campina Grande. Anais do II

CONAPESC. Campina Grande: Editora Realize, 2017. v. 1, p. 1 - 3.

MORÁN, J. M. O vídeo na sala de aula. Comunicação \& Educação, v. 2, p. 27-35, 1995

MOREIRA, Marcos Antônio. MASINI, E. F. S. Aprendizagem significativa: a teoria de David Ausubel. 2. ed. São Paulo: Centauro, 2006.

MOURA, Fábio Andrade de. Ensino de Física por Investigação: Uma Proposta para o Ensino de Empuxo para alunos do Ensino Médio. 2018. 98 f. Dissertação (Mestrado) - Curso de Mestrado Profissional em Ensino de Física, Faculdade de Física, Universidade Federal do Pará, Belém, 2018.

MOURA, Fábio Andrade de; MANDARINO, Pedro Henrique Pastana. Ensino de Física por Investigação: relato de caso sobre uma sequência didática de aulas experimentais no ensino de empuxo. In: Congresso Nacional de Pesquisa e Ensino de Ciências, 2., 2017, Campina Grande. Anais do II CONAPESC. Campina Grande: Editora Realize, 2017. v. 1, p. 1 - 3. Disponível em:

http://editorarealize.com.br/revistas/conapesc/trabalhos/TRABALHO_EV070_MD1_SA5_ID 1591_01052017120918.pdf>. Acesso em: 01 maio 2017.

OLIVEIRA, B. J. (2006). Cinema e imaginário científico. História, ciências, saúdemanguinhos, 13(n. supl), 133-150.

PIASSI, Luís Paulo de Carvalho. Interfaces didáticas entre cinema e ciência. São Paulo: Livraria da Física, 2013. 